\title{
Use of Microprocessor-Based Debug Modules for the Development of GPS (GPRS) and GSM Communication Devices
}

\author{
Murad Omarov \\ ORCID 0000-0003-4842-4972 \\ Department of Natural Sciences \\ Kharkiv National Universityof Radio Electronics \\ Kharkiv, Ukraine \\ murad.omarov@nure.ua \\ Semen Suhorukov \\ Department of MIRES \\ Kharkiv National Universityof Radio Electronics \\ Kharkiv, Ukraine \\ semen.sukhorukov@nure.ua
}

\author{
Roman Tsekhmistro \\ ORCID 0000-0003-3628-3658 \\ Department of MIRES \\ Kharkiv National Universityof Radio Electronics \\ Kharkiv, Ukraine \\ tsekhmistroroman@gmail.com \\ Serhii Shapovalov \\ Department of MIRES \\ Kharkiv National Universityof Radio Electronics \\ Kharkiv, Ukraine \\ serhii.shapovalov@nure.ua
}

\begin{abstract}
This report is devoted to an overview of the technical characteristics and the specifics of the use of modern debugging microprocessor modules for the development of devices for geolocation of objects and data transmission over a mobile communication channel.
\end{abstract}

Keywords-microcontroller system, RASPBERRY PI, arduino ide, GSM(GPS-GPRS)-module

\section{INTRODUCTION}

The success of modern technologies has made it possible to create microprocessor modules for obtaining geolocation data on the location of an object and means of transmitting the received data.

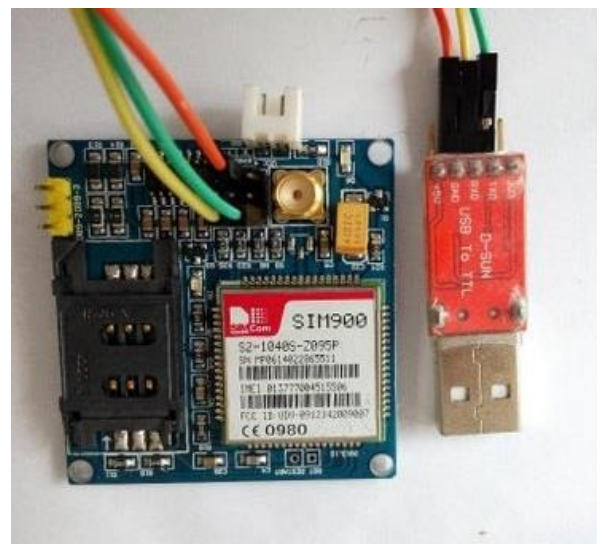

Fig. 1. GSM communication module SIM900 with USB-TTL converter for connection to a computer

One of these modules is shown in fig.1. It is a mobile communication processor, a SIM card socket, a power stabilizer, an interface for communication with a PC and an external microprocessor [2].

SIM800C is the world's smallest GSM / GPRS module in an LCC case with end contacts. Its distinctive features, in addition to its ultra-miniature size, are support for Bluetooth
3.0 at the chipset level, as well as very good indicators of power consumption, RF sensitivity and support for additional features such as DTMF detection / generation, audio file recording / playback, built-in POP3, SMTP protocols, MMS, FTP, HTTP, SSL, etc. Supported by GPRS multi-slot class 12 ( $₫ 85.6 \mathrm{Kbps})$.

The SIM800C module was created by SIMCom Wireless Solutions specifically taking into account the wishes of our customers and has dimensions of only $17.6 * 15.7 \mathrm{~mm}$ and an LCC case with contacts along the perimeter, which implies the possibility of both manual and automated installation.

The Bluetooth transceiver in the module is implemented at the chipset level, so its presence does not affect the cost. Supports SPP, OPP, HFP profiles and work is underway to support additional profiles.

Figure 2 shows the module for determining the satellite coordinates of an object with a ceramic antenna, it has the parameters that are given below [3]:

Power Supply Range: $3 \mathrm{~V}$ to $5 \mathrm{~V}$;

Model: GY-GPS6MV2;

Ceramic antenna; powered off;

EEPROM for saving the configuration data when

Backup battery;

LED signal indicator

Antenna Size: 25 x $25 \mathrm{~mm}$;

Module Size: 25 x 35 mm.;

Mounting Hole Diameter: $3 \mathrm{~mm}$;

Default Baud Rate: 9600 bps. 


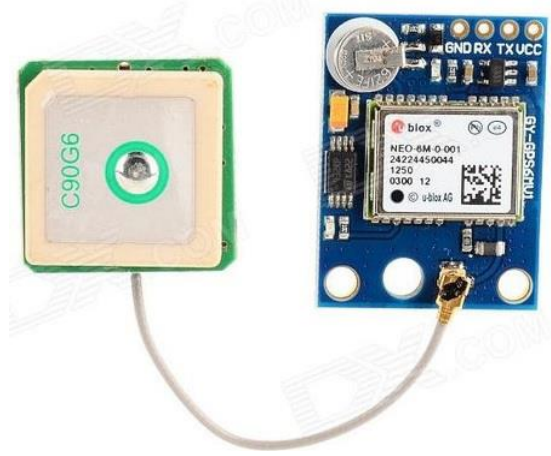

Fig. 2. Module GPS-location Neo-8m ceramic antenna

NEO-6M GPS module with antenna and built-in EEPROM. This is compatible with various flight controller modules that provide GPS computer test software [3].

This board features the u-blox NEO-6M GPS module with antenna and built-in EEPROM. This is compatible with various flight controller boards designed to work with a GPS module.

\section{MAIN PARTS}

Let's consider further the option of using these modules to obtain a GPS location shown at Fig. 3.

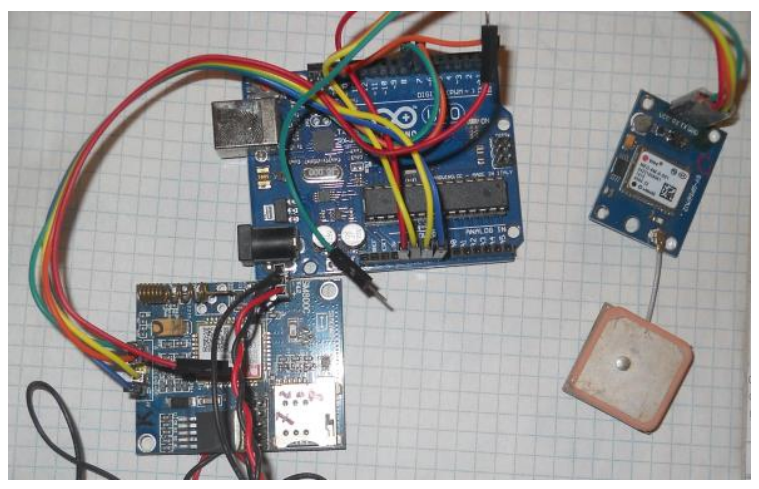

Fig. 3. Application of a laboratory model for determining the geolocation of an object and transmitting their data via mobile communication based on arduino-uno

Overview module a9g-gsm/gprs/gps $32 \mathrm{u} 4$ (arduino leonardo). An alternative to the circuit shown in Fig. 3 is the industrial module presented in Fig. 4 [4].

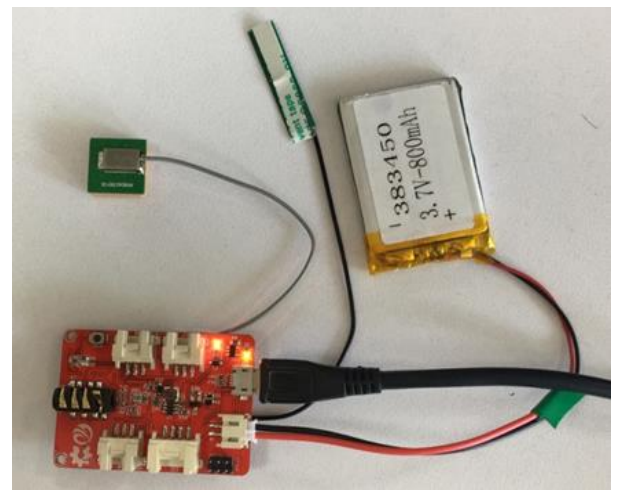

Fig. 4. Module a9g-gsm/gprs/gps $32 \mathrm{u} 4$ view down
The 32U4 with A9g GPRS/GSM/GPS Board is based on Mega32U4 and A9 GPRS/GSM/GPS module.

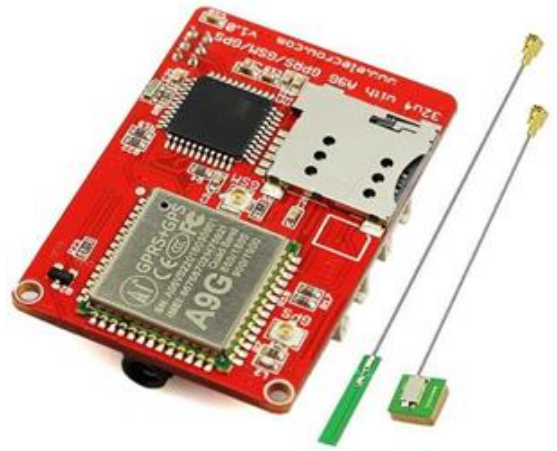

Fig. 5. Module a9g-gsm/gprs/gps $32 \mathrm{u} 4$ view up

It can be used to make a call, send text messages and get GPS positioning. Also it has one analog interface, one IIC interface and two digital interface, which you can connect to other expansion modules. It is very easy for you to make a GPS Tracker by using this board. It is also very easy to use AT firmware and use several AT commands can be configured successfully. Two miniature coaxial RF connector is present on the back of the 32U4 with A9G GPRS/GSM/GPS Board to connect with a GSM antenna or a GPS antenna. The connector present on the 32U4 with A9G GPRS/GSM/GPS is called a U.FL connector [4]. The GSM Antenna supplied with the GPRS Shield has an SMA connector (and not an RP-SMA connector) on it. The connection topology is shown in the diagram below:

- ATMEGA32U4+A9G.

- Work voltage: $3.3 \mathrm{~V}$ to $5 \mathrm{~V}$.

- Operating temperature: $-30{ }^{\circ} \mathrm{C}$ to $+80{ }^{\circ} \mathrm{C}$.

- Three kinds of interfac.

- Equipped with $3.5 \mathrm{~mm}$ headphone jack.

- $\quad 3.7 \mathrm{~V}$ Battery power supply.

- Standby average current 3 ma or less.

- Support the GSM / GPRS/ GPS Quad-band, including $850,900,1800,1900 \mathrm{MHZ}$.

- Support China Mobile and China Unicom's 2G GSM network worldwide.

- GPRS Class 10.

- Sensitivity $<-105$.

- Support GPS Positioning.

- Support for voice calls.

- Support for SMS text messaging.

- Support GPRS data business, the maximum data rate: download 85.6Kbps, upload 42.8Kbps.

- Supports standard GSM07.07, 07.05 AT commands and $\mathrm{Ai}$-Thinker extended commands.

- Supports two serial ports, a serial port to download an AT command port. 
- Support for Global Positioning System.

Horizontal positioning accuracy of less than $2.5 \mathrm{~m}$.

- AT command supports the standard AT and TCP / IP command interface.

- Support digital audio and analog audio support for HR, FR, EFR, AMR speech coding.

The battery socket needs to be connected to $3.7 \mathrm{~V}$ lithium battery, connected to GSM and GPS antenna, and the SIM card slot is inserted into the SIM card slot. Connect the computer to the circuit board via micro USB, as shown in the figure $4-5$.

The following describes how to test the module.

Download the "a9_serial_test.ino" program file to the target board.

Open SSCOM32 serial debugging assistant, serial port baud rate $: 115200 \mathrm{bit} / \mathrm{sec}$.

Test the GPS function. Remember to plug in the GPS antenna.

Send the following command:

- $\quad$ AT return OK;

- $\quad \mathrm{AT}+\mathrm{GPS}=1$ return $\mathrm{OK}$;

$-\mathrm{AT}+\mathrm{GPSRD}=1$ return $\mathrm{OK}$.

An example of testing the A9G module with the arduino platform is given below.

The test itself is implemented with a connected module via the computer's usb port. This test code complies with the Arduino development environment:

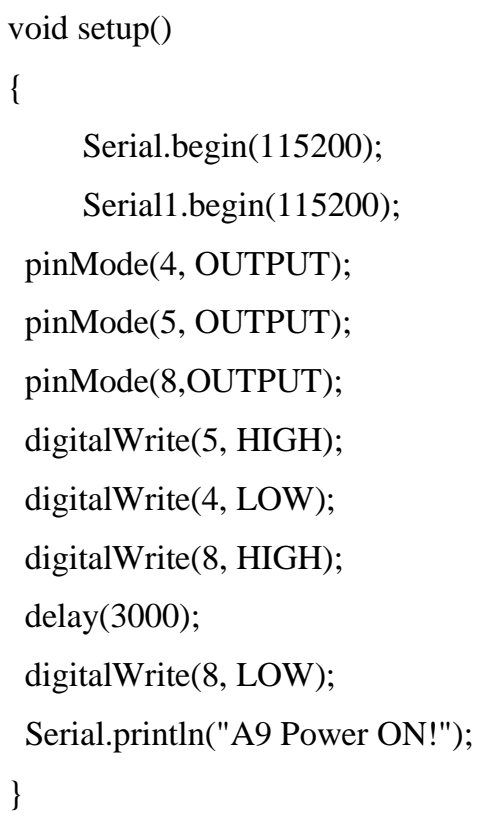

void $\operatorname{loop}()$

\{

char dat;

if(Serial1.available ()$)\{$

dat $=$ Serial1 $\cdot \operatorname{read}()$;

Serial.print(dat);

\}

if(Serial.available ()$)\{$

dat $=$ Serial.read () ;

Serial1.print(dat);

\}

\}

\section{CONCLUSIONS}

The overview of the characteristics of the specified microprocessor modules and ways of their use shows that their compatibility with ARDUINO platform and RASPBERRY PI also debugging kits - STM-32 kits. The example kit is STM-32-OPEN32L-D with STM-32 Discovery. For example, STM-32 use in development of exclusive and pilot projects [5]. The modules under consideration have a wide range of use the A9G module combined with ARDUINO-LEONARDO platform despite the worst parameters of the antenna devises, has much smaller sizes than devises in figure 3 . The size A9G module: $19.2 * 18.8 * 3 \mathrm{~mm}$, size all module (fig. 5 ) $45 * 35 \mathrm{~mm}$. The optimal way to use modules it is creation of tracking systems with GPS-tracks recording.

\section{REFERENCES}

[1] M. Omarov, V. Kartashov and R. Tsekhmistro, "Features of the Use of Microprocessors in the Systems of Ovojectors in their Adaptation to the Conditions of the Former CIS", I International Scientific and Practical Conference, 2019. doi: 10.35598/mcfpga.2019.012.

[2] Elecrow [Online].

Available: https://www.elecrow.com/wiki/index.php?title=GPRS/GSM_Shield_ v1.0http [Accessed: 1- Jun- 2021]

[3] NEO-6_DataSheet [Online]. Available: https://www.ublox.com/sites/default/files/products/documents/NEO6_DataSheet_(GPS.G6-HW-09005).pdf [Accessed: 1- Jun- 2021]

[4] Sensory [Online]. Available: https://www.sensory.com/wpcontent/uploads/80-0225-C.pdf [Accessed: 1- Jun- 2021]

[5] Getting Started with A9G Low Power GSM/GPRS+GPS Module with Arduino [Online]. Available: https://how2electronics.com/a9ggsm-gprs-gps-module-with-arduino [Accessed: 1- Jun- 2021]

[6] Waveshare. File:Open32L-D-Schematic. [Online]. Available: https:// www.waveshare.com/wiki/ Open32L-D [Accessed: 1- Jun- 2021] 